Clin Sports Med. 2011 January ; 30(1): 19-vii. doi:10.1016/j.csm.2010.08.009.

\title{
Biomechanics of Concussion
}

\author{
David F. Meaney, PhDa, ${ }^{*}$ and Douglas H. Smith, $\mathbf{M D}^{\mathrm{b}}$ \\ aDepartment of Bioengineering, University of Pennsylvania, 240 Skirkanich Hall, 210 South 33rd \\ Street, Philadelphia, PA 19104-6392, USA \\ ${ }^{b}$ Department of Neurosurgery, University of Pennsylvania, 105D Hayden Hall, 240 South 33rd \\ Street, Philadelphia, PA 19104-6392, USA
}

\section{Keywords}

Biomechanics; Tolerance; Mild traumatic Brain injury; Concussion

\section{Introduction and Scope}

The recent public awareness of mild traumatic brain injury (TBI) (concussion) and the possible long-term consequences on brain function has raised the profile of the disorder and also highlighted the lack of knowledge on how to effectively treat this disease. For decades, much of the research community concentrated on the most devastating forms of TBI, with the hopes of significantly improving outcome in this patient population. On a relative basis, the incidence of mild TBI far exceeds the number of TBI-related fatalities and moderate/ severe TBIs, with some estimates suggesting its frequency is at least 10 times more common than moderate and severe TBI. ${ }^{1,2}$ Perhaps equally important, comparing the prevalence of patients showing long-term impairment from mild TBI to other diseases is startling: approximately 225,000 new patients each year show long-term deficits from mild TBI, approximately equal to the number of patients diagnosed annually with breast cancer, multiple sclerosis, and traumatic spinal cord injury combined. The emergence of blastinduced TBI from the Iraq and Afghanistan conflicts $^{3-5}$ only heightens the need for a longterm treatment and prevention solution for mild TBI.

The purpose of this article is to provide a review of the past work directed at understanding the biomechanical etiology of concussions. The broad scale of knowledge on this topic is presented, ranging from the measurable mechanical parameters associated with concussion to the underlying mechanisms responsible for tissue damage and the molecular substrates that could form the basis of the immediate, transient impairment observed during a typical concussion episode. Possible future directions are reviewed briefly.

\section{The Mechanical Origins of Concussion-How Does the Head Move?}

There is often confusion about the mechanical etiology of concussions. One primary component of the confusion stems from the many different head motions that can occur when a head is struck with an object or when a head strikes a surface. The protected (helmeted) head has similar variety in the mechanical response. This complex variety of responses makes each injury-causing situation nearly unique. Two broad categories of forces

(C) 2011 Published by Elsevier Inc.

*Corresponding author. dmeaney@seas.upenn.edu.

The authors declare no competing financial interests. 
—contact and inertial—encompass the important causal forces associated with TBIs. Both contact and inertial forces occur during impact loading, where the head is struck (or strikes) a surface. Only inertial (acceleration) loading occurs from impulsive head motions, which are defined by the absence of the head striking an object.

Primary injures caused by direct contact loading can occur both in the region of impact and in regions distant from the impact site. Focal forces are linked to skull fracture and, when focused over a small area, depressed skull fracture. These fractures can lead to subsequent injuries (eg, some linear skull fractures can cause epidural bleeding when the fracture line extends over the blood vessels within the dural membrane). Similarly, there is some evidence suggesting that these stress waves can cause fracture in sites remote from the impact where the skull shows a reduction in its structural or mechanical properties. ${ }^{6}$ The tolerance of the brain to the forces causing these types of contusive injuries is now better characterized $^{7}$ as is the fracture tolerance of the skull to either blunt or more focused impact. ${ }^{8,9}$ These focal brain injuries are common in moderate and severe brain injury but are largely absent in mild TBI. ${ }^{10,11}$ For this reason, the remainder of this review focuses on the inertial forces that cause the concussive injuries common in mild TBI.

There is considerable evidence showing that the primary cause of concussive injuries is the inertial, or acceleration, loading experienced by the brain at the moment of impact. With the head/neck motions that occur during a typical impact, there are two components of acceleration that occur in nearly every instance of concussion - linear and rotational acceleration.

Early efforts to understand the biophysical basis of concussion concentrated on how linear accelerations measured during impact correlated to the corresponding injury thresholds in animals. Recordings of pressure throughout brain surrogates during an impact event showed a good correlation between the peak acceleration and peak pressure at a point within the brain. ${ }^{12,13}$ Although the pressure within the brain during an impact varied, this strong correlation between an internal response (brain pressure) and external input (linear acceleration) led several investigators to study the effects of pressures within the living brain. Several studies established that the transient increase in pressure within the brain causes neurologic dysfunction, with the level of dysfunction correlating with the peak pressure achieved during the injury period. ${ }^{14-16}$

In parallel with these studies on animals, investigators systemically examined the tolerance of the human skull/brain structure to impact loading, with the goal of establishing a primary tolerance curve for injury in humans. Due to their nature-using postmortem samples and filling the cranial vault with gelatin-these studies did not have an ability to measure directly concussion threshold. These studies did, however, measure the relative onset of skull fracture. Some tests also measured the pressures within the brain caused during these impact conditions, providing a reference measure to pressure thresholds derived from animal studies. The tests conducted included drops onto flat surfaces, instrumented samples to measure the acceleration and pressure over time, and correlation of these measurements to the presence/absence of skull fracture. The resulting injury tolerance curve, known commonly as the Wayne State Tolerance Curve, provided the basis for a continuing series of studies to improve the ability to correlate known physical parameters (eg, linear acceleration) to head injury. ${ }^{17-19}$ Largely stimulated by these initial data, there are now testing standards that are used for designing protective equipment and automotive safety systems that use measures of linear acceleration for determining injury risk.

Rotational acceleration is a second type of acceleration that is common during either impact or impulsive head loading. Due to the physical properties of the highly organized brain, ${ }^{20-24}$ 
brain tissue deforms more readily in response to shear forces compared with other biologic tissues. Rapid head rotations generate shear forces throughout the brain, and, therefore, rotational accelerations have a high potential to cause shear-induced tissue damage. The importance of shear forces were confirmed in series of studies across different laboratories, leading to the conventional wisdom that shear deformation caused by rotational acceleration is the predominant mechanism of injury in concussion. ${ }^{25-27}$ If the head motion is constrained to exclude any rotational motion, it is difficult to produce traumatic unconsciousness. In comparison, introducing or allowing a rotational component after impact substantially increases the likelihood of an unconscious episode. ${ }^{28}$ This injury mechanism applies across the severity spectrum; the primary difference across the spectrum is the amount of brain tissue injured and the severity of injury at a given site within the brain. $^{26}$

\section{Mechanisms of Damage-How Does the Mechanical Energy of Motion Transfer to the Tissue?}

A critical component of concussive injuries is how the mechanical energy from the external input (acceleration) is transferred to the brain and vascular tissue at the tissue and microscale. This energy transfer process-both how the acceleration moves and deforms the brain tissues and the effect of this physical stimulus on the living tissue and neural/glial networks-is the key step in understanding the basis for concussion. The critical common denominator in assessing the biomechanics of concussion is defining conditions that cause internal responses (eg, strain and pressure) within the brain and understanding the combination of external input conditions resulting in these conditions.

Brain is one of the softest biologic materials, shows nonlinear behavior, and changes its properties in response to the applied loading rate. ${ }^{20-24}$ Composed largely of water, brain material is resistant to changing its shape when subjected to either slow or transient pressures. Brain tissue deforms easily, however, when shearing forces are applied. These two internal responses (pressure and shear) are the main metrics used to describe the mechanical response of the brain to an applied external loading input.

Past work shows that linear acceleration correlates well as a predictor of the peak pressures that occur within the brain. ${ }^{29} \mathrm{~A}$ simple model of the hydrostatic gradients generated within the brain can provide a rudimentary approximation of these pressures and can also predict the effect of pressure-relieving openings (eg, foramen magnum) on the resulting pressure gradients. ${ }^{30}$ Experimental measures of the human surrogate response to impact loading also provide key insight into how local impact from a blunt impactor causes a subsequent acceleration of the head and pressure gradient within the cranial contents. Based on these data, the ability to predict, a priori, the pressures generated within the brain under a known external loading condition has improved substantially with the advancement of computationally based finite element models in the past two decades (for recent publications, see Refs. ${ }^{20,31-35}$ ). Some versions of these computational models are becoming highly detailed, allowing investigators to examine if the ventricular system and/or blood vessel network influences measured pressure gradients within the tissue during inertial loading. ${ }^{36}$ Similarly, the effects of these pressure gradients on the deformations that can occur within the brain are also better known. Early studies using photoelastic gelatin indicate that pressure gradients during linear acceleration-based motions can create strains at the craniocervical junction. Subsequent work studying common models of pressure-induced brain injury in animals show a similar type of ability to enhance strains in the brain-stem. ${ }^{37}$ These data also indicate, however, that the strains induced by pressure gradients within the brain are much smaller than the strains caused by rotational accelerations, primarily because the brain material deforms little in response to pressure. When considering strictly the 
pressures generated within the brain during typical acceleration conditions associated with concussions, this past work provides a solid foundation for prescribing the accurate pressure conditions at any point within the brain.

In contrast to pressures generated within the brain during impact or impulsive loading, the tissue deformation (strain) is influenced primarily by the applied rotational accelerations, the intracranial partitioning membranes, and the material properties of the brain tissue. For a given magnitude of rotational acceleration, the resulting patterns of strain within the brain are markedly different if the acceleration is applied in the coronal (lateral), horizontal (axial), or sagittal plane. Experimental data show the effect of rotational acceleration direction on the corresponding impairment, with lateral (coronal) plane accelerations in humans showing the most likelihood for producing damage within the deep internal structures of the brain. ${ }^{26}$ Although neurologic impairment (loss of consciousness) is produced most readily with coronal plane motions, it is possible to generate similar impairment with rotational motions along the horizontal and sagittal planes, albeit these acceleration magnitudes are higher. The principle of directionally dependent brain damage is confirmed in a series of studies across different species ${ }^{26,38}$ and is a critical factor in understanding the human tolerance to injuries, such as concussion. The ventricular system may have an important damping effect on the strains that appear throughout the brain during rotational motions, and the membranes that partition the cerebral hemispheres and the cerebellum from the cerebrum also influence the patterns on deformation that appear for a given head motion. ${ }^{39,40}$

The ability to predict the strains that appear throughout the brain during rotational motions is challenging, because the large deformations that appear during typical injury-causing situations often require advanced computational and experimental methods. Initial efforts to model the behavior of brain surrogates in simplified models of the human brain/skull showed encouraging correlation with experimental data. ${ }^{20,31}$ Next-generation models included more accurate anatomic detail of the brain structures along specific anatomic planes and suggested the complex interface between white and gray matter, as well as the presence of fluid-filled ventricles, were important 2-D model features affecting the predicted mechanical response of the brain. ${ }^{41}$

Studies extending these computational models into 3-D representations of the living brain are ongoing and proceeding along two complementary directions. First, development of a more idealized 3-D geometry with the inclusion of major anatomic features is under continuous development. Published work shows that this simplified model produces approximately the same brain motions measured in human surrogate tests and that this tool can scan many possible injury scenarios quickly for a quick assessment of the situations that could produce focal or more diffuse brain injuries. ${ }^{20,31}$ One of the initial goals of this project - developing rapid computational results on a desktop computer-makes this approach most feasible for the designers of safety and protective equipment to quickly assess the brain injury risk for any loading input. One primary benefit of this simplified computational tool is the use as a proactive design tool for testing and developing new protective equipment.

The second approach uses a more highly detailed 3-D model of the brain within the skull and can produce exceptionally detailed predictions on the local and global response of the brain to any impact or impulsive loading scenario (example studies are included in Refs. ${ }^{32,34,35,42-46}$ ). Multiscale modeling techniques with this highly detailed approach suggest it may be even possible to predict the deformations applied to networks of blood vessels and neural/glial cells, opening up a critically important window in understanding how the externally applied loading can cause local changes in vascular, neural, and glial behavior. ${ }^{36}$ With this detailed knowledge, there is a substantial increase in the computational 
time needed to develop predictions. As computational power and modeling algorithms becomes more advanced, these models will eventually become available for rapid use on desktop computers. The most widely used current role for these models, however, is for researchers and not designers.

\section{How is the Brain Affected from the Mechanical Energy Transfer During Concussion?}

\section{Studying the Effect at the Microscale-What Is Known}

As more was learned about the transfer of the external input (contact and inertial loading) into the brain mechanical response, it became clear that the key to understanding the basis for the immediate impairment in mild TBI was measuring the effect of these mechanical forces on the blood vessels and cellular networks within the brain. Studying these effects is technically challenging, because the forces need to be applied quickly ( $<50$ milliseconds). In addition, the modeling of impact response showed that the deformations within the brain can be significant during injury and the systems for studying the effects at the microscale needed to apply these large deformations quickly. Finally, the deformation field occurring within the brain needed to be recreated accurately in these microinjury models.

Despite these technical challenges, several groups showed that the effect of an appropriately tuned mechanical stimulation is broad and complex. In dissociated cells, much of the early work focused on how a single, rapid deformation of cell monolayers (astrocytes, endothelial cells, and mixed cultures of neurons and glia) would cause alterations in acute biochemical signaling and affect long-term viability. Astrocytes respond to a focal mechanical stimulation by propagating intercellular waves through their network. Mechanically stimulated astrocyte networks show changes in the cytoskeleton, organelle function, and biochemical cascades over time. ${ }^{47-54}$ Many of these initial changes point to an alteration in the homeostatic mechanisms of astrocyte regulation.

The response of neurons to microinjury is probably the most well characterized, with the most diverse approaches developed to study this response. It is possible to measure the response of cellular populations. The range of physical manipulations spans the spectrum from a mild physical insult with no obvious structural changes to an insult capable of transecting subcellular elements. Early evidence showed that these physical insults can affect the properties of important synaptic glutamate receptors that can regulate neurotransmission and plasticity in networks. ${ }^{55}$ Moreover, inhibitory synaptic receptor functions can be altered with a physical force, showing that the balance of excitation/ inhibition coupling is important to consider when assessing the effects of these physical forces. ${ }^{56}$ Perhaps equally important is the alteration in the receptor composition and intracellular signaling that occurs after a microinjury. Several studies indicate that an initial injury to neuronal culture can lead to subsequent change in the response of neurons to an agonist stimulation, some of which are linked to the appearance of new glutamate receptor types at the synapse. ${ }^{33,57,58}$ Moreover, there is clear evidence that physical injury can lead to activation of different neuronal death pathways, with the physical coupling of glutamate receptors potentially explaining part of this activation process. ${ }^{59-61}$ Studies indicate the response of neural networks to repeated injuries is not simply the superposition of the response to an individual insult. ${ }^{62}$ This is a critical observation for studying concussive brain injuries.

Rather than coupling the mechanical insult directly to intracellular signaling through mechanoactivated receptors and channels, several studies indicate an alternative mechanism of damage — an immediate, nonspecific increase in plasma membrane permeability. ${ }^{63-65}$ The increase in membrane permeability is not long-lasting, because data suggest membrane 
resealing within 10 to 15 minutes. ${ }^{64}$ The relative influence of this mechanism to the mechanoactivation of receptors and channels remains to be fully described. But there is work suggesting the deformation field applied to monolayers (eg, stretch applied in one direction versus two perpendicular directions) is a primary determinant that dictates the contributing role of each mechanism. ${ }^{66}$ This relative threshold would help explain the diversity of responses in the literature; some studies do not show any immediate change in membrane permeability whereas others attribute the entire postinjury response to this mechanism of damage.

The technologies for studying injury at the microscale extend to the study of subcellular elements, which may be particularly important for neurons, where the subcellular organization is key for network function. Early technologies studied how the transection of a neuronal process affects signaling within the soma and defined a critical distance between the soma and the lesion site to effect changes on nuclear gene expression. ${ }^{67,68}$ Technology to mechanically injure processes first appeared more than a decade ago, where networks of axons bridging two populations of neurons could be stretched and studied over time. ${ }^{69,70}$ The corresponding threshold for immediate changes in biochemical (calcium-mediated) signaling was established as were approximate thresholds for structural changes and tearing of the axonal processes. Moreover, studies using this system showed that the voltage-gated sodium channels are mechanoactivated from the stretch event and undergo a rapid proteolysis that can lead to a sustained elevation of axoplasmic calcium. ${ }^{71,72}$ This proteolysis is activated at stretch levels below the structural failure threshold and are, therefore, potentially relevant for concussive type injuries where axonal transection is rare, if present at all.

An advantage of the microscale technologies (discussed previously) is that many of these methods are scalable to more complex tissue preparations. A more advanced representation of living tissue is the organotypic brain slice culture, which contains both the neural and glial network in an architecture that more closely resembles the in vivo brain. With the ability to culture slices of the brain for long periods of time (approximately 3-4 weeks), these cultures can be mechanically stretched to mimic the deformations that occur within the brain over the entire severity spectrum of TBI. ${ }^{73-75}$ To date, reports show the ability to study the expression of different genes in response to injury levels below the threshold to cause neuronal death, to study the effect of targeted therapeutic treatments when the level of mechanical injury exceeds the tolerance for cell death, and to define region-specific thresholds for cell death in critical brain regions (eg, hippocampus) associated with mild TBI. ${ }^{76-78}$ Recent advances in multielectrode array recording make it possible to record changes in the network ensemble after mechanical injury on stretchable array platforms. ${ }^{79-83}$ The versatility of this technology has yet to be fully developed, but this shows promise in providing a number of possible output parameters (function, biochemical, and genomic) in a more realistic tissue environment compared with monolayer cultures.

The second major category of mechanical input in concussion situations is the pressure generated transiently through the brain. In cultured cells, the effects of pressure are studied much less than the effects of deformation. Slowly applied pressure can alter cell function in astrocytes and neurons, but the tested pressures are much higher than the pressure experienced during a typical concussion-type insult. ${ }^{84}$ Applying rapid pressure changes to a fluid-filled chamber containing either brain slice or primary cell cultures can lead to biochemical changes and neural dysfunction, but thresholds for these changes are not well established. ${ }^{85-89}$ Repeated impacts of a fluid-filled chamber into a striking plate also caused primary changes in neural cultures. It is difficult, however, to separate the effects of the deceleration during the repeated impacts from the pressures generated in the chamber for these impacts..$^{90}$ 


\section{Studying the Effects at the Microscale-What Is Not Known}

At the microscale, work in the past two decades shows that the mechanical forces in the brain during TBI are capable of triggering both initial and postacute changes in function. In some studies, the forces applied are enough to cause cell death over the ensuing hours and days. ${ }^{73,77}$ The mechanisms that regulate the response of the networks have been well studied. Less attention has been paid to the mechanical threshold for triggering these changes. Already, work is emerging to define regional thresholds for cell death in important regions of the brain (eg, hippocampus), with obvious impact on the function of networks in the affected brain region. The threshold at which a deficit appears, however, may be much lower than the level necessary to cause neuronal or glial death. This functional threshold may have an important bearing on conditions associated with concussion. For example, a recent study shows the threshold for astrocyte reactivity is well below the threshold for causing changes in astrocyte viability after stretch. This threshold is also below the level necessary to cause neuronal death. ${ }^{47}$ These data lead to obvious questions- - How does the neural network behave in the presence of these reactive astrocytes? Does this lead to a change in the synaptic plasticity of the network? The effects from the mechanical force insult may have long-lasting changes in the network that occur from interactions among two or more cell types. Defining the persistence of these changes over time will have an important bearing on understanding when forces at the microscale have a corresponding effect on function at either the micro- or macroscale.

\section{Merging the Microscale with the Macroscale: Role of Emerging Field Studies}

In parallel with the efforts to describe the effect of mechanical forces on neural and glial cell networks, there is a renewed emphasis on defining the field conditions associated with concussions. In many sports, the emergence of concussion as a major health issue has occurred within the past 10 years, possibly from the increased awareness of how multiple concussions early in life can affect the risk for developing neurodegenerative disease later in life. ${ }^{91-93}$ Defining the externally applied forces and accelerations experienced by the head at the time of concussive brain injury is a critically important complement to past work and ongoing studies. Normally, work at this level is difficult to match with work at the other end of the spectrum, namely microscale injury studies. Because of the advances of computational models that bridge the gap between applied external loading and the intracranial strains, however, there is now a clear opportunity to merge knowledge across the scales to define a more comprehensive view of concussions.

In an analysis of professional football players, Pellman, and colleagues ${ }^{94,95}$ surveyed concussions occurring in the field of play and used reconstruction techniques to establish a concussion threshold. In comparison to reconstructing single concussion cases, recent technology embedding accelerometers into helmets (head impact telemetry system [HITS]) allows researchers to constantly sample the accelerations experienced by players during game and practice situations. ${ }^{96-98}$ The data collected between the two methods show some similarity and will provide important information for basic researchers to estimate the real world scenarios that cause concussion. Moreover, these monitoring efforts will likely inform new product designs and also offer the ability to track the effectiveness of these new helmet designs in the field of play to complement design studies conducted in the laboratory.

\section{Looking to the Future}

Although the biomechanics of concussion is a research area that spans many length scales, there is now substantial work across these scales that establish a coordinated approach for better understanding of concussive brain injury and how new technologies can be developed 
to reduce the incidence of concussion. Methods are in place to estimate how the brain moves and deforms under common conditions associated with concussion; these computational methods are increasingly robust for predicting the mechanical response of the brain under many different situations. In parallel, field studies are defining the real world situations that cause concussions and comparing them to similar situations that do not cause concussions. These surveillance data provide critical input for the computational tools that will continue to improve the resolution and accuracy of estimating strains within specific anatomic regions. With new techniques to map these deformations to strains of cellular and vessel networks within the brain, a wealth of information from microscale studies will merge with information from large-scale studies. These combined efforts will define how different cell types are damaged during concussion and provide a method to rationally develop new technologies for reducing or preventing concussions in the field.

\section{Acknowledgments}

Funding provided by NIH NS35712, HD41699, and NS056202.

\section{References}

1. Bazarian JJ, McClung J, Shah MN, et al. Mild traumatic brain injury in the United States, 19982000. Brain Inj. 2005; 19(2):85-91. [PubMed: 15841752]

2. Langlois JA, Rutland-Brown W, Wald MM. The epidemiology and impact of traumatic brain injury: a brief overview. J Head Trauma Rehabil. 2006; 21(5):375-8. [PubMed: 16983222]

3. Eibner C, Schell TL, Jaycox LH. Care of war veterans with mild traumatic brain injury. N Engl J Med. 2009; 361(5):537. author reply: 537-8. [PubMed: 19645085]

4. Preiss-Farzanegan SJ, Chapman B, Wong TM, et al. The relationship between gender and postconcussion symptoms after sport-related mild traumatic brain injury. PM R. 2009; 1(3):245-53. [PubMed: 19627902]

5. Xydakis MS, Robbins AS, Grant GA. Mild traumatic brain injury in U.S. soldiers returning from Iraq. N Engl J Med. 2008; 358(20):2177. author reply: 2179. [PubMed: 18480213]

6. McElhaney JH, Hopper RH Jr, Nightingale RW, et al. Mechanisms of basilar skull fracture. J Neurotrauma. 1995; 12(4):669-78. [PubMed: 8683618]

7. Shreiber DI, Smith DH, Meaney DF. Immediate in vivo response of the cortex and the blood-brain barrier following dynamic cortical deformation in the rat. Neurosci Lett. 1999; 259(1):5-8. [PubMed: 10027542]

8. Raymond D, Van Ee C, Crawford G, et al. Tolerance of the skull to blunt ballistic temporo-parietal impact. J Biomech. 2009; 42(15):2479-85. [PubMed: 19674749]

9. Yoganandan N, Pintar FA. Biomechanics of temporo-parietal skull fracture. Clin Biomech (Bristol, Avon). 2004; 19(3):225-39.

10. Graham DI, Adams JH, Nicoll JA, et al. The nature, distribution and causes of traumatic brain injury. Brain Pathol. 1995; 5(4):397-406. [PubMed: 8974622]

11. Adams JH, Doyle D, Graham DI, et al. The contusion index: a reappraisal in human and experimental non-missile head injury. Neuropathol Appl Neurobiol. 1985; 11(4):299-308. [PubMed: 4058674]

12. Gurdjian ES, Lissner HR, Evans FG, et al. Intracranial pressure and acceleration accompanying head impacts in human cadavers. Surg Gynecol Obstet. 1961; 113:185-90. [PubMed: 13709837]

13. Thomas LM, Roberts VL, Gurdjian ES. Experimental intracranial pressure gradients in the human skull. J Neurol Neurosurg Psychiatr. 1966; 29(5):404-11. [PubMed: 5926463]

14. Lindgren S, Rinder L. Experimental studies in head injury. II. Pressure propagation in "percussion concussion". Biophysik. 1966; 3(2):174-80. [PubMed: 5982794]

15. Gurdjian ES, Lissner HR, Webster JE, et al. Studies on experimental concussion: relation of physiologic effect to time duration of intracranial pressure increase at impact. Neurology. 1954; 4(9):674-81. [PubMed: 13214267] 
16. Denny-Brown DE, Russell WR. Experimental concussion: (section of neurology). Proc R Soc Med. 1941; 34(11):691-2. [PubMed: 19992388]

17. Gurdjian ES, Webster JE, Lissner HR. The mechanism of skull fracture. J Neurosurg. 1950; 7(2): 106-14. [PubMed: 15405316]

18. Gurdjian ES, Webster JE, Lissner HR. Studies on skull fracture with particular reference to engineering factors. Am J Surg. 1949; 78(5):736-42. Disc 749-51. [PubMed: 15391184]

19. Gurdjian ES, Lissner HR, Webster JE. The mechanism of production of linear skull fracture; further studies on deformation of the skull by the stresscoat technique. Surg Gynecol Obstet. 1947; 85(2):195-210. [PubMed: 20253085]

20. Takhounts EG, Crandall JR, Darvish K. On the importance of nonlinearity of brain tissue under large deformations. Stapp Car Crash J. 2003; 47:79-92. [PubMed: 17096245]

21. Miller K, Chinzei K. Constitutive modelling of brain tissue: experiment and theory. J Biomech. 1997; 30(11-12):1115-21. [PubMed: 9456379]

22. Donnelly BR, Medige J. Shear properties of human brain tissue. J Biomech Eng. 1997; 119(4): 423-32. [PubMed: 9407281]

23. Arbogast KB, Thibault KL, Pinheiro BS, et al. A high-frequency shear device for testing soft biological tissues. J Biomech. 1997; 30(7):757-9. [PubMed: 9239559]

24. Prange MT, Meaney DF, Margulies SS. Defining brain mechanical properties: effects of region, direction, and species. Stapp Car Crash J. 2000; 44:205-13. [PubMed: 17458728]

25. Unterharnscheidt F, Higgins LS. Traumatic lesions of brain and spinal cord due to nondeforming angular acceleration of the head. Tex Rep Biol Med. 1969; 27(1):127-66. [PubMed: 4976573]

26. Gennarelli TA, Thibault LE, Adams JH, et al. Diffuse axonal injury and traumatic coma in the primate. Ann Neurol. 1982; 12(6):564-74. [PubMed: 7159060]

27. Adams JH, Graham DI, Murray LS, et al. Diffuse axonal injury due to nonmissile head injury in humans: an analysis of 45 cases. Ann Neurol. 1982; 12(6):557-63. [PubMed: 7159059]

28. Ommaya AK, Gennarelli TA. Cerebral concussion and traumatic unconsciousness. Correlation of experimental and clinical observations of blunt head injuries. Brain. 1974; 97(4):633-54. [PubMed: 4215541]

29. Nahum AM, Smith R, Ward CC. Intracranial pressure dynamics during head impact. in 21st Annual Stapp Car Crash Conference. Society of Automotive Engineers. 1977

30. Stalhammar D, Olsson Y. Experimental brain damage from fluid pressures due to impact acceleration. Acta Neurol Scand. 1975; 52:38-55. [PubMed: 1155026]

31. Takhounts EG, Ridella SA, Hasija V, et al. Investigation of traumatic brain injuries using the next generation of simulated injury monitor (SIMon) finite element head model. Stapp Car Crash J. 2008; 52:1-31. [PubMed: 19085156]

32. Ishikawa R, Kato K, Kubo M, et al. Finite element analysis and experimental study on mechanism of brain injury using brain model. Conf Proc IEEE Eng Med Biol Soc. 2006; 1:1327-30. [PubMed: 17945634]

33. Bell JD, Ai J, Chen Y, et al. Mild in vitro trauma induces rapid Glur2 endocytosis, robustly augments calcium permeability and enhances susceptibility to secondary excitotoxic insult in cultured Purkinje cells. Brain. 2007; 130(Pt 10):2528-42. [PubMed: 17664176]

34. Franklyn M, Fildes B, Zhang L, et al. Analysis of finite element models for head injury investigation: reconstruction of four real-world impacts. Stapp Car Crash J. 2005; 49:1-32. [PubMed: 17096266]

35. Zhang L, Yang KH, Dwarampudi R, et al. Recent advances in brain injury research: a new human head model development and validation. Stapp Car Crash J. 2001; 45:369-94. [PubMed: 17458754]

36. Zhang L, Bae J, Hardy WN, et al. Computational study of the contribution of the vasculature on the dynamic response of the brain. Stapp Car Crash J. 2002; 46:145-64. [PubMed: 17096223]

37. Thibault LE, Meaney DF, Anderson BJ, et al. Biomechanical aspects of a fluid percussion model of brain injury. J Neurotrauma. 1992; 9(4):311-22. [PubMed: 1291691]

38. Smith DH, Nonaka M, Miller R, et al. Immediate coma following inertial brain injury dependent on axonal damage in the brainstem. J Neurosurg. 2000; 93(2):315-22. [PubMed: 10930019] 
39. Ivarsson J, Viano DC, Lovsund P. Influence of the lateral ventricles and irregular skull base on brain kinematics due to sagittal plane head rotation. J Biomech Eng. 2002; 124(4):422-31. [PubMed: 12188208]

40. Ivarsson J, Viano DC, Lovsund P, et al. Strain relief from the cerebral ventricles during head impact: experimental studies on natural protection of the brain. J Biomech. 2000; 33(2):181-9. [PubMed: 10653031]

41. Nishimoto T, Murakami S. Relation between diffuse axonal injury and internal head structures on blunt impact. J Biomech Eng. 1998; 120(1):140-7. [PubMed: 9675693]

42. Zhang L, Yang KH, King AI. A proposed injury threshold for mild traumatic brain injury. J Biomech Eng. 2004; 126(2):226-36. [PubMed: 15179853]

43. Takahashi T, Kato K, Ishikawa R, et al. 3-D finite element analysis and experimental study on brain injury mechanism. Conf Proc IEEE Eng Med Biol Soc. 2007; 2007:3613-6. [PubMed: 18002779]

44. Li J, Zhang J, Yoganandan N, et al. Regional brain strains and role of falx in lateral impactinduced head rotational acceleration. Biomed Sci Instrum. 2007; 43:24-9. [PubMed: 17487052]

45. Zhang J, Yoganandan N, Pintar FA, et al. Role of translational and rotational accelerations on brain strain in lateral head impact. Biomed Sci Instrum. 2006; 42:501-6. [PubMed: 16817658]

46. Zhang L, Yang KH, King AI. Comparison of brain responses between frontal and lateral impacts by finite element modeling. J Neurotrauma. 2001; 18(1):21-30. [PubMed: 11200247]

47. Miller WJ, Leventhal I, Scarsella D, et al. Mechanically induced reactive gliosis causes ATPmediated alterations in astrocyte stiffness. J Neurotrauma. 2009; 26(5):789-97. [PubMed: 19331521]

48. Charles AC, Merrill JE, Dirksen ER, et al. Intercellular signaling in glial cells: calcium waves and oscillations in response to mechanical stimulation and glutamate. Neuron. 1991; 6(6):983-92. [PubMed: 1675864]

49. Di X, Goforth PB, Bullock R, et al. Mechanical injury alters volume activated ion channels in cortical astrocytes. Acta Neurochir Suppl. 2000; 76:379-83. [PubMed: 11450049]

50. Floyd CL, Rzigalinski BA, Weber JT, et al. Traumatic injury of cultured astrocytes alters inositol (1,4,5)-trisphosphate-mediated signaling. Glia. 2001; 33(1):12-23. [PubMed: 11169788]

51. Hoffman SW, Rzigalinski BA, Willoughby KA, et al. Astrocytes generate isoprostanes in response to trauma or oxygen radicals. J Neurotrauma. 2000; 17(5):415-20. [PubMed: 10833060]

52. Ahmed SM, Rzigalinski BA, Willoughby KA, et al. Stretch-induced injury alters mitochondrial membrane potential and cellular ATP in cultured astrocytes and neurons. J Neurochem. 2000; 74(5):1951-60. [PubMed: 10800938]

53. Rzigalinski BA, Willoughby KA, Hoffman SW, et al. Calcium influx factor, further evidence it is 5, 6-epoxyeicosatrienoic acid. J Biol Chem. 1999; 274(1):175-82. [PubMed: 9867827]

54. Lamb RG, Harper CC, McKinney JS, et al. Alterations in phosphatidylcholine metabolism of stretch-injured cultured rat astrocytes. J Neurochem. 1997; 68(5):1904-10. [PubMed: 9109516]

55. Zhang L, Rzigalinski BA, Ellis EF, et al. Reduction of voltage-dependent Mg2+ blockade of NMDA current in mechanically injured neurons. Science. 1996; 274(5294):1921-3. [PubMed: 8943207]

56. Kao CQ, Goforth PB, Ellis EF, et al. Potentiation of GABA(A) currents after mechanical injury of cortical neurons. J Neurotrauma. 2004; 21(3):259-70. [PubMed: 15115601]

57. Spaethling JM, Klein DM, Singh P, et al. Calcium-permeable AMPA receptors appear in cortical neurons after traumatic mechanical injury and contribute to neuronal fate. J Neurotrauma. 2008; 25(10):1207-16. [PubMed: 18986222]

58. Bell JD, Park E, Ai J, et al. PICK1-mediated GluR2 endocytosis contributes to cellular injury after neuronal trauma. Cell Death Differ. 2009; 16(12):1665-80. [PubMed: 19644508]

59. Cui H, Hayashi A, Sun HS, et al. PDZ protein interactions underlying NMDA receptor-mediated excitotoxicity and neuroprotection by PSD-95 inhibitors. J Neurosci. 2007; 27(37):9901-15. [PubMed: 17855605]

60. Aarts M, Liu Y, Liu L, et al. Treatment of ischemic brain damage by perturbing NMDA receptorPSD-95 protein interactions. Science. 2002; 298(5594):846-50. [PubMed: 12399596] 
61. Sattler R, Xiong Z, Lu WY, et al. Specific coupling of NMDA receptor activation to nitric oxide neurotoxicity by PSD-95 protein. Science. 1999; 284(5421):1845-8. [PubMed: 10364559]

62. Weber JT, Rzigalinski BA, Willoughby KA, et al. Alterations in calcium-mediated signal transduction after traumatic injury of cortical neurons. Cell Calcium. 1999; 26(6):289-99. [PubMed: 10668567]

63. LaPlaca MC, Cullen DK, McLoughlin JJ, et al. High rate shear strain of three-dimensional neural cell cultures: a new in vitro traumatic brain injury model. J Biomech. 2005; 38(5):1093-105. [PubMed: 15797591]

64. Geddes DM, Cargill RS 2nd, LaPlaca MC. Mechanical stretch to neurons results in a strain rate and magnitude-dependent increase in plasma membrane permeability. J Neurotrauma. 2003; 20(10):1039-49. [PubMed: 14588120]

65. Geddes DM, LaPlaca MC, Cargill RS 2nd. Susceptibility of hippocampal neurons to mechanically induced injury. Exp Neurol. 2003; 184(1):420-7. [PubMed: 14637111]

66. Geddes-Klein DM, Schiffman KB, Meaney DF. Mechanisms and consequences of neuronal stretch injury in vitro differ with the model of trauma. J Neurotrauma. 2006; 23(2):193-204. [PubMed: 16503803]

67. Lucas JH. Proximal segment retraction increases the probability of nerve cell survival after dendrite transection. Brain Res. 1987; 425(2):384-7. [PubMed: 3427440]

68. Lucas JH, Gross GW, Emery DG, et al. Neuronal survival or death after dendrite transection close to the perikaryon: correlation with electrophysiologic, morphologic, and ultrastructural changes. Cent Nerv Syst Trauma. 1985; 2(4):231-55. [PubMed: 3836011]

69. Wolf JA, Stys PK, Lusardi T, et al. Traumatic axonal injury induces calcium influx modulated by tetrodotoxin-sensitive sodium channels. J Neurosci. 2001; 21(6):1923-30. [PubMed: 11245677]

70. Smith DH, Wolf JA, Lusardi TA, et al. High tolerance and delayed elastic response of cultured axons to dynamic stretch injury. J Neurosci. 1999; 19(11):4263-9. [PubMed: 10341230]

71. von Reyn CR, Spaethling JM, Mesfin MN, et al. Calpain mediates proteolysis of the voltage-gated sodium channel alpha-subunit. J Neurosci. 2009; 29(33):10350-6. [PubMed: 19692609]

72. Iwata A, Stys PK, Wolf JA, et al. Traumatic axonal injury induces proteolytic cleavage of the voltage-gated sodium channels modulated by tetrodotoxin and protease inhibitors. J Neurosci. 2004; 24(19):4605-13. [PubMed: 15140932]

73. Morrison B 3rd, Cater HL, Wang CC, et al. A tissue level tolerance criterion for living brain developed with an in vitro model of traumatic mechanical loading. Stapp Car Crash J. 2003; 47:93-105. [PubMed: 17096246]

74. Morrison B 3rd, Meaney DF, Margulies SS, et al. Dynamic mechanical stretch of organotypic brain slice cultures induces differential genomic expression: relationship to mechanical parameters. J Biomech Eng. 2000; 122(3):224-30. [PubMed: 10923289]

75. Morrison B 3rd, Eberwine JH, Meaney DF, et al. Traumatic injury induces differential expression of cell death genes in organotypic brain slice cultures determined by complementary DNA array hybridization. Neuroscience. 2000; 96(1):131-9. [PubMed: 10683418]

76. Elkin BS, Morrison B 3rd. Region-specific tolerance criteria for the living brain. Stapp Car Crash J. 2007; 51:127-38. [PubMed: 18278594]

77. Cater HL, Sundstrom LE, Morrison B 3rd. Temporal development of hippocampal cell death is dependent on tissue strain but not strain rate. J Biomech. 2006; 39(15):2810-8. [PubMed: 16289515]

78. Morrison B 3rd, Cater HL, Benham CD, et al. An in vitro model of traumatic brain injury utilising two-dimensional stretch of organotypic hippocampal slice cultures. J Neurosci Methods. 2006; 150(2):192-201. [PubMed: 16098599]

79. DeRidder MN, Simon MJ, Siman R, et al. Traumatic mechanical injury to the hippocampusin vitro causes regional caspase- 3 and calpain activation thatis influenced by NMDA receptor subunit composition. Neurobiol Dis. 2006; 22(1):165-76. [PubMed: 16356733]

80. Yu Z, Elkin BS, Morrison B. Quantification of functional alterations after in vitro traumatic brain injury. Conf Proc IEEE Eng Med Biol Soc. 2009; 2009:1135-8. [PubMed: 19963487] 
81. Yu Z, Graudejus O, Lacour SP, et al. Neural sensing of electrical activity with stretchable microelectrode arrays. Conf Proc IEEE Eng Med Biol Soc. 2009; 2009:4210-3. [PubMed: 19964344]

82. Yu Z, Morrison B 3rd. Experimental mild traumatic brain injury induces functional alteration of the developing hippocampus. J Neurophysiol. 2010; 103(1):499-510. [PubMed: 19923245]

83. Yu Z, Graudejus O, Tsay C, et al. Monitoring hippocampus electrical activity in vitro on an elastically deformable microelectrode array. J Neurotrauma. 2009; 26(7):1135-45. [PubMed: 19594385]

84. Murphy EJ, Horrocks LA. A model for compression trauma: pressure-induced injury in cell cultures. J Neurotrauma. 1993; 10(4):431-44. [PubMed: 8145266]

85. Panizzon KL, Shin D, Frautschy S, et al. Neuroprotection with Bcl-2(20-34) peptide against trauma. Neuroreport. 1998; 9(18):4131-6. [PubMed: 9926861]

86. Girard J, Panizzon K, Wallis RA. Azelastine protects against CA1 traumatic neuronal injury in the hippocampal slice. Eur J Pharmacol. 1996; 300(1-2):43-9. [PubMed: 8741163]

87. Wallis RA, Panizzon KL, Girard JM. Traumatic neuroprotection with inhibitors of nitric oxide and ADP-ribosylation. Brain Res. 1996; 710(1-2):169-77. [PubMed: 8963656]

88. Panizzon KL, Dwyer BE, Nishimura RN, et al. Neuroprotection against CA1 injury with metalloporphyrins. Neuroreport. 1996; 7(2):662-6. [PubMed: 8730852]

89. Wallis RA, Panizzon KL. Felbamate neuroprotection against CA1 traumatic neuronal injury. Eur J Pharmacol. 1995; 294(2-3):475-82. [PubMed: 8750708]

90. Lucas JH, Wolf A. In vitro studies of multiple impact injury to mammalian CNS neurons: prevention of perikaryal damage and death by ketamine. Brain Res. 1991; 543(2):181-93. [PubMed: 1711911]

91. Kiraly M, Kiraly SJ. Traumatic brain injury and delayed sequelae: a review-traumatic brain injury and mild traumatic brain injury (concussion) are precursors to later-onset brain disorders, including early-onset dementia. ScientificWorldJournal. 2007; 7:1768-76. [PubMed: 18040539]

92. Guskiewicz KM, Marshall SW, Bailes J, et al. Association between recurrent concussion and latelife cognitive impairment in retired professional football players. Neurosurgery. 2005; 57(4):71926. discussion: 719-26. [PubMed: 16239884]

93. Stern MB. Head trauma as a risk factor for Parkinson's disease. Mov Disord. 1991; 6(2):95-7. [PubMed: 2057017]

94. Viano DC, Casson IR, Pellman EJ. Concussion in professional football: biomechanics of the struck player-part 14. Neurosurgery. 2007; 61(2):313-27. discussion: 327-8. [PubMed: 17762744]

95. Pellman EJ, Viano DC, Tucker AM, et al. Concussion in professional football: location and direction of helmet impacts-Part 2. Neurosurgery. 2003; 53(6):1328-40. discussion: 1340-1. [PubMed: 14633299]

96. Manoogian S, McNeely D, Duma S, et al. Head acceleration is less than 10 percent of helmet acceleration in football impacts. Biomed Sci Instrum. 2006; 42:383-8. [PubMed: 16817638]

97. Brolinson PG, Manoogian S, McNeely D, et al. Analysis of linear head accelerations from collegiate football impacts. Curr Sports Med Rep. 2006; 5(1):23-8. [PubMed: 16483513]

98. Duma SM, Manoogian SJ, Bussone WR, et al. Analysis of real-time head accelerations in collegiate football players. Clin J Sport Med. 2005; 15(1):3-8. [PubMed: 15654184] 